\title{
THE DETECTION OF MYC PROTEINS IN THE DEVELOPING HUMAN KIDNEY
}

\author{
Běla Erdösová, Filip Wagner, Dana Kylarová
}

\author{
Department of Histology and Embryology, Faculty of Medicine, Palacký University, Olomouc, Czech Republic \\ e-mail:erdos@tunw.upol.cz
}

Received: September 20, 2004

Key words: Myc family/C-myc/N-myc/Apoptosis/Nephrogenesis/Bcl-2 family

The aim of our work was the detection of c- and N- myc proteins in the developing kidney of human fetuses especially in the neogenous zone. These proteins being localized in nucleus and encoded by the cellullar oncogene myc function as transcriptional factors. Myc gene represents the key control gene in the course of cellular proliferation and differentiation. It also participates in the regulation of apoptosis and the origin of some cancers. Both proteins have been proved to be inevitable for proper nephrogenesis in mice. Considering the dearth of studies dealing with human embryonic tissues, we attempted to map the localization and spatiotemporal relations of the expression of these proteins during human nephrogenesis. In addition, issuing from our previous observations, we tried to compare their ways of expression with those of Bcl-2 (antiapoptotic effect) and Bax (proapoptotic function) proteins. Histologically normal kidneys were collected from eight human fetuses ranging from the $10^{\text {th }}-30^{\text {th }}$ week of IUD. Tissue samples were fixed in methacarn and processed by routine paraffin technique. Standard indirect three-step immunohistochemical method was applied for the detection of $\mathrm{N}$ - and c-myc proteins. In the neogenous zone both proteins are markedly present in metanephrogenic blastema with declining intensity with the increasing age of fetus. Branches of ureteral bud are almost negative. Such localization is also typical for Bcl-2 protein whereas Bax positive cells are present mostly in branches of the ureteral bud. It is not clear if all these proteins collaborate in the course of regulation of apoptosis in human metanephros.

\section{INTRODUCTION}

$\mathrm{N}$ - and c- myc proteins encoded by the cell oncogene myc are localized in nucleus and act as transcriptional factors. They are involved in all the vital cellular processes. Myc gene represents a key control gene during cell proliferation and differentiation. It sensitizes cell to apoptosis and participates in the origin of some tumors ${ }^{1}$. Myc proteins are antagonized by Mad which is another member of the myc protein family ${ }^{2}$. C-myc -/- mice show grave retardation and congenital defects in many developing organs and embryonic structures leading to death at day 10 of IUD, thus before kidney development begins. Overexpression of C-myc is involved in the pathogenesis of polycystic kidney disease ${ }^{3}$.

$\mathrm{N}$-myc protein is inevitable for nephrogenesis as demonstrated in mice. Complete $\mathrm{N}$-myc gene disruption results in fetal death on the first day of renal organogenesis (the $11^{\text {th }}$ day of IUD) whereas lowered expression leads to renal hypoplasia being characterized by quite preserved structure with reduced number of developing glomeruli and collecting canaliculi ${ }^{4}$. There is a strong evidence of $\mathrm{N}$-myc involvement in the regulation of GDNF and c-ret ligand, growth factors inevitable for nephrogenesis ${ }^{5}$.

Considering the scantiness of studies dealing with human embryonic tissues, we attempted to map the localization and spatiotemporal relations of the expression of these proteins during human nephrogenesis. In addition, issuing from our previous observations, we tried to compare their modes of expression with those of Bcl-2 (antiapoptotic effect) and Bax (proapoptotic function) proteins.

\section{MATERIAL AND METHODS}

Histologically normal kidneys were collected from eight human fetuses ranging from the $10^{\text {th }}-30^{\text {th }}$ week of IUD ( $10^{\text {th }}, 13^{\text {th }}, 18^{\text {th }}, 22^{\text {nd }}, 25^{\text {th }}$ and $30^{\text {th }}$ week $)$. Tissue samples were fixed in methacarn and processed by routine paraffin technique. The standard indirect three-step immunohistochemical method was applied for the detection of N-and c-myc proteins using Mab c-myc (9E10) and $\mathrm{Mab}_{\mathrm{IgG}_{2 \mathrm{a}}}$ to N-myc (both Santa Cruz Biotechnology). For visualization was used either horse radish peroxidase (DAB as a substrate, final colouring reddish brown and hematoxylin for counterstaining) or alkaline phosphatase (substrate NBT/BCIP resulting in dark blue precipitate, nuclear red for counterstaining). A double staining method was carried out to demonstrate colocalization of two proteins (c-myc and Bax) on one slide using the above mentioned Mab to c-myc and Mab to Bax (Immunotech). 


\section{RESULTS}

$\mathrm{N}$ - and c-myc positive cells were found in almost all structures of the neogenous zone, both in uninduced and induced metanephrogenic mesenchyme (metanephrogenic blastema), in comma- and S-shaped bodies, forming renal corpuscles and the earliest primitive tubuli though with different intensity of expression and number of positive cells Fig. 1). The outcomes show that both proteins occur markedly, especially in metanephrogenic blastema. The intensity of expression and number of positive cells decline with increasing age of fetus. Though neogenous zone diminishes during the fetal period, the mesenchymo-epithelial transformation of metanephrogenic mesenchyme (i.e. reciprocal inductions between branches of ureteral bud and uninduced mesenchyme) persists till the $35^{\text {th }}$ week of IUD. The mode of expression of both proteins retains similar character as seen in earlier fetal periods, i.e. pronounced in caps of induced mesenchyme circling branches of ureteral bud and disperse appearance of single cells in all the structures of the neogenous zone: uninduced mesenchyme (single cells or small groups) comma- and S-shaped bodies, newly forming renal corpuscles and the earliest primitive tubuli. Branches of ureteral bud are negative. Only deeper, more mature parts of future collecting tubuli are sporadically positive. The strongest expression of both proteins was found in the earliest age (the $10^{\text {th }}$ week IUD). A significant divergence in the localization of the proteins under study has not been observed.

As mentioned before, on older fetuses $\left(25^{\text {th }}\right.$ and $30^{\text {th }}$ weeks IUD) the intensity of expression and number of positive cells decrease which is obvious especially in neogenous zone. In deeper parts of differentiating parenchyma we observed a contrast between renal corpuscles with rare both c- and $\mathrm{N}$-myc positive cells and epithelials of tubuli where these cells are more abundant and the intensity of expression stronger. The decrease in positive

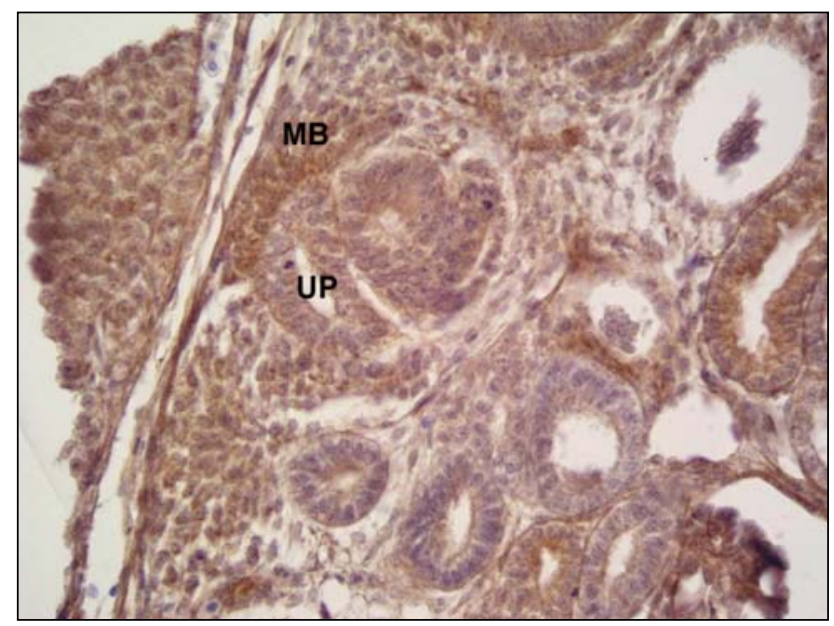

Fig. 1. Neogenous zone of metanephros - c-myc positive cells in metanephrogenic blastema (MB) being in contrast with negative nuclei in branches of ureteral bud (UP). 10-week-old fetus. Magn. 400x. cells is pronounced especially in deeper glomeruli in contrast to immature ones.

The outcomes of the double staining method (Bax/ c-myc) are similar to those acquired from monostaining, i.e. c-myc positive cells in induced mesenchyme and Bax positive cells in branches of ureteral bud.

\section{CONCLUSIONS AND DISCUSSION}

Comparing findings acquired from murine developing kidneys, we have found out some parallels with our observations. Branches of ureteral bud both in mice and our human material are almost negative ${ }^{6}$. Coming from our previous studies, protein Bax was quite of highly expressed in branches of ureteral bud where, on the contrary, Bcl-2 showed almost null expression. Whereas in mice c-myc occurs mostly in uninduced metanephrogenic and N-myc in induced mesenchyme, in human metanephros the majority of c-and $\mathrm{N}$-myc positive cells is found in caps of induced metanephrogenic mesenchyme surrounding branches of ureteral bud. With regard to their roles in proliferation and accompanying apoptosis, it is not surprising, that both proteins appear especially in rapidly proliferating and thus condensing induced mesenchyme.This finding correlates with the occurrence of antiapoptotic Bcl-2 protein which appears mostly in induced mesenchyme, too (Fig. 2). The latter protects induced cells and gives them a chance to survive while uninduced mesenchyme is doomed to die ${ }^{7}$. From this finding we can not conclude that the coincidence also implies their co-operation in the course of apoptosis regulation. Transgenic mice with polycystic kidney disease (PKD) show overexpression of c-myc and have a very high apoptotic index. However, the level of Bcl-2, Bax and p53 is not higher in comparison with controls. Double transgenic mice overexpressing both c-myc and Bcl-2 suffer from similar PKD and the apoptotic index is as high as in the

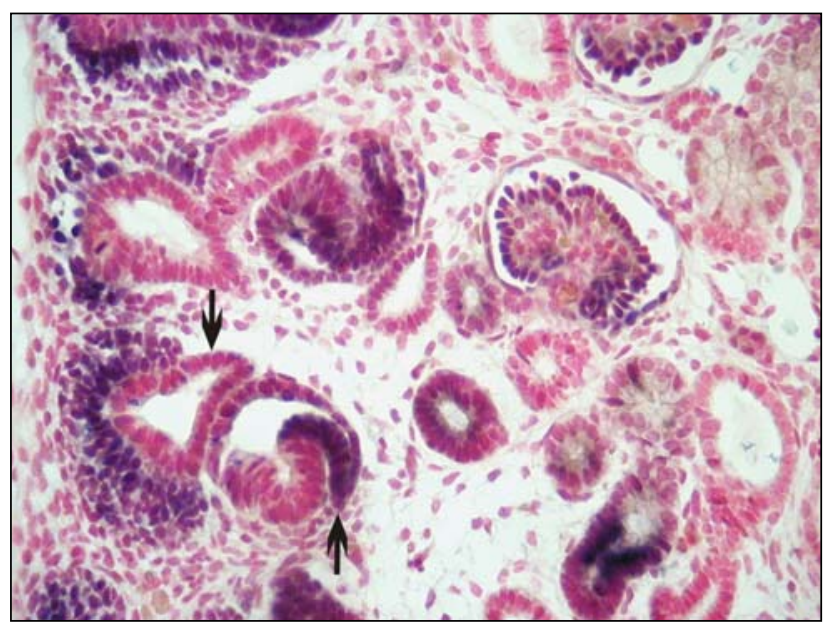

Fig. 2. Neogenous zone of metanephros - Bcl-2 + cells in metanephrogenic blastema and negative branches of ureteral bud $(\downarrow)$. Bcl- $2+$ cells in tubule $(\uparrow)$. 13-week-old fetus. Magn. 400 x. 
previous case. It implies that the protective influence of Bcl-2 is not involved ${ }^{3}$. Since this conclusion comes from nonphysiological conditions (overexpression of Bcl-2), this implication need not be valid for physiological regulation of apoptosis. Nevertheless, some authors mention that neither Bax, dimerizing partner of Bcl-2, nor p53 (via Bax) participate in apoptosis intermediated by c-myc ${ }^{3}$ while others produce evidence of the functional cooperation c-myc with $\mathrm{Bax}^{8,9,10}$. The complexity and ambiguity of apoptotic regulation can be etched in by the discovery that Bcl-2 molecules can be cleaved by caspases. Thus, the cleaved form can antagonize full-length protein ${ }^{11}$.

$\mathrm{N}$-myc plays a pivotal role during murine nephrogenesis. Studies on murine kidney explants show that a lower level of $\mathrm{N}$-myc is closely connected with the reduction of branches of the ureteral bud and fewer glomeruli. It is not clear whether N-myc affects branching directly or by means of an unknown secondary mechanism The fact that branches of the ureteral bud are N-myc negative both in mice and men favours the latter opinion, e.g. via growth factors GDNF and c-ret ligand ${ }^{5}$. It is highly probable that murine hypoplastic kidneys resulting from lower level of $\mathrm{N}$-myc are a consequence of a decrease in cell proliferation and not an increase in apoptosis ${ }^{4}$.

The c- and N-myc positive cell number and intensity of expression declines with age. To complete kidney development, both proliferation and apoptosis (and myc gene involved in these processes, too) must be switched off in the end. This finding correlates with our observations being characterized by a decreasing number of proliferating and apoptotic cells in the late fetal period.

The fact that no significant divergence in localization of proteins under study has been registered may be a consequence of coexpression ${ }^{1}$. The double staining method would be helpful in this case.

Our descriptive study may contribute to complete our knowledge of myc proteins as a whole.

\section{ACKNOWLEDGEMENT}

This study was supported by grant MSMT 15100001.

\section{REFERENCES}

1. Hatton KS, Mahon K, Chin L, Chiu FCH, Lee H-W, Peng D, Morgenbesser SD, Horner J, and DePinho RA (1996) Expression and activity of L-myc in normal mouse development. Mol Cell Biol, 1794-1804.

2. Chin L, Schreiber-Agus N, Pellicer I, Chen K, Lee H, Dudast M, Cordon-Cardo C, and DePinho RA. (1995) Contrasting roles for Myc and Mad proteins in cellular growth and differentiation. Proc Natl Acad Sci USA, 92, 8488-8492, Developmental Biology

3. Trudel M, Lanoix J, Barisoni L, Blouin MJ, Desforges M, L'Italien, and D'Agati V. (1997) C-MYC-induced apoptosis in polycystic kidney disease is Bcl-2 and p53 independent. J Exp Med The Rockefeller University Press. Vol. 186, Number 11, 18731884.

4. Bates CM, Kharzai S, Erwin T, Rossant J, and Parada LF. (2000) Role of N-myc in the developing mouse kidney. Developmental Biology 222, 317-325.

5. Schuchardt A, D’Agati V, Larsson-Blomberg L, Constantini F, and Pachnis V. (1994) Defects in the kidney and the enteric nervous systém of mice lacking tyrosine kinase receptor Ret Nature 367, 380-383.

6. Patterson LT, and Dressler GR. (1994)The regulation of kidney development: new insights from an old model. Curr Opin Genet Dev 4, 696-702.

7. Sorenson CM. (1998) Life, death and kidneys: regulation of programmed cell death. Curr Opin Nephr \& Hypertension 7, 5-12.

8. Mitchell KO, Ricci MS, Miyashita T, Dicker DT, Jin Z, Reed JC, El-Deiry WS. (2000) Bax is a transcriptional target and mediator of c-myc induced apoptosis. Cancer Research 60, 6348-6325.

9. Juin P, Hunt A, Littlewood T, Griffiths B, Brown Swigart L, Korsmeyer S, and Evan G. (2002) C-myc functionally cooperates with Bax to induce apoptosis. Mol Cell Biol, 6158-1169

10. Hengartner M. (2000) The biochemistry of apoptosis. Nature 407, $770-776$ 